\title{
Targeting the PI3K signaling pathway in cancer
}

\author{
Kwok-Kin Wong ${ }^{1,2,3}$, Jeffrey A Engelman ${ }^{1,4}$, and Lewis C Cantley $1,5,6$ \\ ${ }^{1}$ Department of Medicine, Harvard Medical School, Boston MA 02115 \\ 2 Department of Medical Oncology, Dana-Farber Cancer Institute, Boston, MA 02115 \\ ${ }^{3}$ Ludwig Center at Dana-Farber/Harvard Cancer Center, Boston, MA 02115 \\ ${ }^{4}$ Massachusetts General Hospital Cancer Center, Harvard Medical School, Charlestown, MA 02129 \\ ${ }^{5}$ Department of Systems Biology, Harvard Medical School, Boston, MA 02115 \\ ${ }^{6}$ Division of Signal Transduction, Beth Israel Deaconess Medical Center, Boston, MA 02115
}

\begin{abstract}
The PI3K pathway is activated in a variety of different human cancers, and inhibitors of this pathway are under active development as anti-cancer therapeutics. In this review, we discuss the data supporting the use of PI3K pathway inhibitors in genetically and clinically defined cancers. This review focuses on their efficacy as single-agents and in combination with other targeted therapies, specifically those targeting the MEK-ERK signaling pathway.
\end{abstract}

\section{Introduction}

The phosphoinositide 3-kinases (PI3Ks) are a family of lipid kinases that propagate intracellular signaling cascades regulating a wide range of cellular processes. PI3K phosphorylates the 3'-OH group on phosphatidylinositols in the plasma membrane. This leads to recruitment of the protein Ser/Thr-kinase, AKT, to the cell membrane where it becomes activated. The PI3K/AKT signaling cascade is critical in cancer as it promotes cell survival and growth (for reviews, see references [1-4]. PI3K-AKT signaling is activated in cancers by several different mechanisms [2]. Somatic mutations in PIK3CA, the gene encoding the p110 $\alpha$ catalytic subunit have been identified in a variety of solid tumors [5], and they are most frequently observed in two hotspots: the helical domain (E545K and E542K) and the kinase domain (H1047R). These mutations have been shown to be transforming in vitro and in vivo [6-8]. Receptor tyrosine kinases, such as EGFR, HER2 and PDGFR, that are activated in many cancers also engage the PI3K pathway. Furthermore, $\mathrm{p} 110$ has been shown to bind RAS directly thereby providing a potential biochemical link between RAS and PI3K signaling. PTEN, a phosphatase that degrades the phosphoinositide products of PI3K, is frequently lost in many different cancer types, including prostate, breast and brain cancers [9]. Lastly, activating mutations in AKT have also been recently reported in breast cancers [10]. Thus, the PI3K signaling pathway is speculated to be one of the crucial core pathways for cancer development and maintenance (for review, see Engelman et al, Nature Cancer Review) [2]. The ubiquitous nature of PI3K pathway activation in cancer suggests that PI3K, AKT and other components

\footnotetext{
Publisher's Disclaimer: This is a PDF file of an unedited manuscript that has been accepted for publication. As a service to our customers we are providing this early version of the manuscript. The manuscript will undergo copyediting, typesetting, and review of the resulting proof before it is published in its final citable form. Please note that during the production process errors may be discovered which could affect the content, and all legal disclaimers that apply to the journal pertain.
} 
of this pathway may be attractive targets for cancer therapy, and multiple PI3K pathway inhibitors are now under active clinical development.

\section{PI3K pathway in tumor development, maintenance and acquired resistance}

Recent genetic studies have provided additional mechanistic insights into the role of PI3K pathway in various aspects of cancer progression and response to treatment. Murine established lung cancers induced by mutant $P I K 3 C A(H 1047 R)$ are quite highly sensitive toPI3K inhibitors. In addition, preclinical studies demonstrate that breast cancer cell lines with PIK3CA mutations are sensitive to PI3K-mTOR and AKT inhibitors [11,12]. These studies provide a clear preclinical rationale for the development of this class of agents in the group of lung cancer patients whose tumors harbor these activating PIK3CA oncogenic drivers [13]. In contrast, treatment of established murine lung cancers driven by endogenous mutant Kras with the same PI3K inhibitors did not result in tumor shrinkage [13]. This is in agreement with cell line data suggesting that KRAS mutant cancer lines are not sensitive to single-agent PI3K pathway inhibitors [14]. These data contrast the elegant work of Downward and colleagues who found that the RAS binding domain of $\mathrm{p} 110 \alpha$ is required for lung tumorigenesis in the LA2 Kras G12 mouse model. In that study, mice were engineered with a mutation in the RAS binding domain of p1 $10 \alpha[15]$. This mutation abrogated the ability of Kras G12D to induce lung tumors (i.e. tumorigenesis). Similarly, we observed that genetic deletion of the PI3K regulatory subunit impairs KRAS induced lung tumorigenesis [13]. Thus, these studies suggest that loss of PI3K function may impair tumorigenesis, and this might serve an effective strategy in chemoprevention in patients with high risk of developing KRAS driven lung cancer. Importantly, these data as a whole underscore that blocking tumorigenesis and shrinking established tumors are not equivalent. Although PI3K activation may be important for KRAS induced tumorigenesis, PI3K activity is not essential for maintenance and survival of established cancers. Thus, drugs targeting this pathway do not appear to have potent anti-tumor activity in established KRAS cancers when used as single-agents.

\section{Activation of ERBB3 and PI3K signaling as a mechanism of acquired resistance to TKIs targeting EGFR and HER2}

Tyrosine kinase inhibitors (TKIs) of EGFR and HER2 are active in subsets of lung and breast cancers. In particular, lung cancers that harbor the EGFR kinase domain mutations respond to small molecule EGFR inhibitors such as gefitinib and erlotinib. Unfortunately, after a median duration of response of 10 to 12 months, all cancers invariably develop resistance [16]. The most common mechanism of acquired resistance is the development of a secondary EGFR mutation, T790M which increases the affinity of the EGFR for ATP, thereby reducing the efficacy of these drugs [17]. Recently other mechanisms of resistance to EGFR TKIs that do not involve acquisition of a T790M were discovered. The first one that we identified was the amplification of the MET oncogene. Amplification of MET leads to resistance because as MET is overexpressed, it activates ERBB3 independently of EGFR (or HER2), and thus is able to maintain downstream signaling (both PI3K and ERK) in the presence of gefitinib.

Amplification of MET was shown in 4/18 (22\%) of patients with acquired resistance to gefitinib or erlotinib [18]. In addition, a study led by Dr. Pao also identified MET amplification in 20\% of cases of acquired resistance [19]. In addition, some EGFR driven cancer cell lines develop resistance by maintaining PI3K signaling due to activation of the IGF-IR signaling pathway [20]. Interestingly, another recent study by Dr. Moasser and colleagues demonstrated that reactivation of ERBB3/PI3K signaling occurs when breast cancers become resistant to incomplete HER2 inhibition [21]. Furthermore, Junttila and colleagues found that a PI3K inhibitor can inhibit the growth of HER2-amplified trastuzumab resistant tumors with PIK3CA mutations [22]. Thus, it appears that re-activation of PI3K pathway activity (via ERBB3dependent and independent mechanisms) is associated with acquired resistance to TKIs in 
EGFR and HER2 addicted cancers. Thus, PI3K pathway inhibitors might be an effective component of a therapeutic strategy to overcome the acquired resistance.

\section{Concurrent PI3K related genetic alterations in cancer and implication for therapy}

It is intriguing that PIK3CA activating mutations are often present with other concurrent genetic alterations that activate the PI3K pathway. PTEN loss (breast, endometrium and colon), RAS activating mutations (colon) and HER2 amplifications (breast) are frequently found with PIK3CA mutations multiple cancer types [23]. One likely explanation is that the sole activation of the PI3K pathway is not sufficient for transformation in many cancer types. Activation of non-overlapping transduction pathways, such as the MEK or Ral-GDS pathways, may be needed for full malignant transformation in these tissues. In addition, multiple mutations impacting the PI3K pathway may circumvent negative feedback loops and synergistically amplify the PI3K transformation signal. Lastly, in the case of PTEN loss in the nascent cancer cell in these tissue types, the subsequent PI3K genetic alterations might be necessary to overcome initial PTEN loss induced p53 dependent cellular senescence [23]. Thus, for cancers with multiple mutations that engage PI $3 \mathrm{~K}$ pathways, it is likely that PI $3 \mathrm{~K}$ inhibitors, as single agents, will elicit minimal responses, and that combination therapy will be necessary for significant efficacy.

\section{Single agent PI3K inhibition therapy and combination therapy in different genetically defined cancers}

With recent availability of PI3K pathway inhibitors, there have been strong ongoing efforts in examining the activity of these agents used either singly or in combination with other targeted therapeutics in the treatment of various genetically defined cancers. As discussed above, we recently observed that a highly specific PI3K-mTOR inhibitor can dramatically shrink p110 H1047R driven lung adenocarcinomas. In addition, PI3K-mTOR inhibitors, as single agents, can also cause dramatic apoptosis in HER2 amplified cancer and PIK3CA mutant cancer cells $[11,24]$. In contrast, PI3K-mTOR inhibitor treatment did not induce dramatic cell death of EGFR kinase domain mutant driven lung cancer cells in vitro or in vivo [24]. However, the combination of PI3K and MEK inhibition caused dramatic cell death with EGFR driven cancer cells and shrinkage of established EGFR driven lung adenocarcinomas. This PI3K/MEK combination caused concomitant down-regulation of Mcl-1 (PI3K inhibition driven) and upregulation of BIM (MEK inhibition driven) [25-28], thereby conspiring to promote apoptosis (Figure 1). Interestingly, in HER2 amplified cancer cells, inhibition of the PI3K pathway does not affect Mcl-1 protein expression demonstrating that the PI3K pathway regulates apoptotic proteins differently in EGFR and HER2 addicted cancers. In addition, It is worth noting that AKT/MEK inhibition combination did not generate a similar robust response apoptotic response in EGFR mutant lung cancers, further implicating that the effect of PI3K inhibition is mediated by an AKT-independent pathway downstream of PI3K or mTOR [24]. This highlights the potential important therapeutic differences between inhibiting PI3K and inhibiting AKT as recently demonstrated by Garraway and colleagues in PIK3CA mutant cancers [29].

Although the Kras induced lung cancers were not sensitive to single-agent PI3K inhibitors, the PI3K/MEK inhibition combination produced dramatic responses in established Kras driven lung adenocarcinomas. Of note, in that study, combined treatment with a PI3K-mTOR and a MEK inhibitor were necessary to downregulate S6 phosphorylation and promote dramatic apoptosis in vivo [13]. Recently, additional studies have demonstrated the effectiveness of combined PI3K and MEK inhibition in other types of cancers as well [30-32]. In total, these preclinical data provide very strong rationale to test PI $3 \mathrm{~K}$ inhibitors either as a single agent in 
HER2 amplified and PIK3CA mutated cancers, or in combination with a MEK inhibitor in patients KRAS or EGFR mutated cancers.

\section{Future directions}

With the development of multiple inhibitors that target the PI3K pathways (such as the p110 inhibitors and AKT inhibitors), it will be important to understand the role of PI3K-AKT dependent and independent pathways in cancer maintenance and progression in specific cancer types. These findings will quickly be translated into generating better strategies to optimize their use in cancer clinical trials. In this era of personalized medicine in which cancers are genotyped for the most common genetic alterations, there is a great opportunity to efficiently develop drugs targeting the PI3K pathway to optimally benefit patients with cancer.

\section{References}

1. Cantley LC. The phosphoinositide 3-kinase pathway. Science 2002;296:1655-1657. [PubMed: 12040186]

2. Engelman JA. Targeting PI3K signalling in cancer: opportunities, challenges and limitations. Nat Rev Cancer 2009;9:550-562. [PubMed: 19629070]

3. Engelman JA, Luo J, Cantley LC. The evolution of phosphatidylinositol 3-kinases as regulators of growth and metabolism. Nat Rev Genet 2006;7:606-619. [PubMed: 16847462]

4. Vivanco I, Sawyers CL. The phosphatidylinositol 3-Kinase AKT pathway in human cancer. Nat Rev Cancer 2002;2:489-501. [PubMed: 12094235]

5. Samuels Y, Velculescu VE. Oncogenic mutations of PIK3CA in human cancers. Cell Cycle 2004;3:1221-1224. [PubMed: 15467468]

6. Isakoff SJ, Engelman JA, Irie HY, Luo J, Brachmann SM, Pearline RV, Cantley LC, Brugge JS. Breast cancer-associated PIK3CA mutations are oncogenic in mammary epithelial cells. Cancer Res 2005;65:10992-11000. [PubMed: 16322248]

7. Samuels Y, Diaz LA Jr, Schmidt-Kittler O, Cummins JM, Delong L, Cheong I, Rago C, Huso DL, Lengauer C, Kinzler KW, et al. Mutant PIK3CA promotes cell growth and invasion of human cancer cells. Cancer Cell 2005;7:561-573. [PubMed: 15950905]

8. Samuels Y, Ericson K. Oncogenic PI3K and its role in cancer. Curr Opin Oncol 2006;18:77-82. [PubMed: 16357568]

9. Li J, Yen C, Liaw D, Podsypanina K, Bose S, Wang SI, Puc J, Miliaresis C, Rodgers L, McCombie $\mathrm{R}$, et al. PTEN, a putative protein tyrosine phosphatase gene mutated in human brain, breast, and prostate cancer. Science 1997;275:1943-1947. [PubMed: 9072974]

10. Carpten JD, Faber AL, Horn C, Donoho GP, Briggs SL, Robbins CM, Hostetter G, Boguslawski S, Moses TY, Savage $\mathrm{S}$, et al. A transforming mutation in the pleckstrin homology domain of AKT1 in cancer. Nature 2007;448:439-444. [PubMed: 17611497]

11 . Serra V, Markman B, Scaltriti M, Eichhorn PJ, Valero V, Guzman M, Botero ML, Llonch E, Atzori F, Di Cosimo S, et al. NVP-BEZ235, a dual PI3K/mTOR inhibitor, prevents PI3K signaling and inhibits the growth of cancer cells with activating PI3K mutations. Cancer Res 2008;68:8022-8030. This study demonstrated that breast cancers with HER2 amplification or PIK3CA mutations are particularly sensitive to dual PI3K-mTOR inhibitors. [PubMed: 18829560]

12•. She QB, Chandarlapaty S, Ye Q, Lobo J, Haskell KM, Leander KR, DeFeo-Jones D, Huber HE, Rosen N. Breast tumor cells with PI3K mutation or HER2 amplification are selectively addicted to Akt signaling. PLoS One 2008;3:e3065. This study demonstrated that breast cancers with HER2 amplification or PIK3CA mutations are particularly sensitive to AKT inhibitors. [PubMed: 18725974]

13••. Engelman JA, Chen L, Tan X, Crosby K, Guimaraes AR, Upadhyay R, Maira M, McNamara K, Perera SA, Song Y, et al. Effective use of PI3K and MEK inhibitors to treat mutant Kras G12D and PIK3CA H1047R murine lung cancers. Nat Med 2008;14:1351-1356. This study demonstrated that PIK3CA is oncogenic in the murine lung epithelium and that PI3K inhibition can cause dramatic shrinkage of the PI3K driven lung cancers. In addition, the authors showed that combined PI3K 
and MEK inhibition in vivo is an effective treatment for KRAS mutated lung cancers. [PubMed: 19029981]

14. Ihle NT, Lemos R Jr, Wipf P, Yacoub A, Mitchell C, Siwak D, Mills GB, Dent P, Kirkpatrick DL, Powis G. Mutations in the phosphatidylinositol-3-kinase pathway predict for antitumor activity of the inhibitor PX-866 whereas oncogenic Ras is a dominant predictor for resistance. Cancer Res 2009;69:143-150. [PubMed: 19117997]

15. Gupta S, Ramjaun AR, Haiko P, Wang Y, Warne PH, Nicke B, Nye E, Stamp G, Alitalo K, Downward $\mathrm{J}$. Binding of ras to phosphoinositide 3-kinase p110alpha is required for ras-driven tumorigenesis in mice. Cell 2007;129:957-968. [PubMed: 17540175]

16. Engelman JA, Janne PA. Mechanisms of acquired resistance to epidermal growth factor receptor tyrosine kinase inhibitors in non-small cell lung cancer. Clin Cancer Res 2008;14:2895-2899. [PubMed: 18483355]

17. Yun CH, Mengwasser KE, Toms AV, Woo MS, Greulich H, Wong KK, Meyerson M, Eck MJ. The T790M mutation in EGFR kinase causes drug resistance by increasing the affinity for ATP. Proc Natl Acad Sci U S A 2008;105:2070-2075. [PubMed: 18227510]

18•. Engelman JA, Zejnullahu K, Mitsudomi T, Song Y, Hyland C, Park JO, Lindeman N, Gale CM, Zhao X, Christensen J, et al. MET amplification leads to gefitinib resistance in lung cancer by activating ERBB3 signaling. Science 2007;316:1039-1043. This manuscript showed that amplification of c-MET is one of the main mechanisms of acquired resistance to EGFR TKIs in lung cancer patients whose cancer harbors EGFR kinase domain mutations. [PubMed: 17463250]

19. Bean J, Brennan C, Shih JY, Riely G, Viale A, Wang L, Chitale D, Motoi N, Szoke J, Broderick S, et al. MET amplification occurs with or without T790M mutations in EGFR mutant lung tumors with acquired resistance to gefitinib or erlotinib. Proc Natl Acad Sci U S A 2007;104:20932-20937. [PubMed: 18093943]

20. Guix M, Faber AC, Wang SE, Olivares MG, Song Y, Qu S, Rinehart C, Seidel B, Yee D, Arteaga $\mathrm{CL}$, et al. Acquired resistance to EGFR tyrosine kinase inhibitors in cancer cells is mediated by loss of IGF-binding proteins. J Clin Invest 2008;118:2609-2619. [PubMed: 18568074]

21. Sergina NV, Rausch M, Wang D, Blair J, Hann B, Shokat KM, Moasser MM. Escape from HERfamily tyrosine kinase inhibitor therapy by the kinase-inactive HER3. Nature 2007;445:437-441. [PubMed: 17206155]

22•. Junttila TT, Akita RW, Parsons K, Fields C, Lewis Phillips GD, Friedman LS, Sampath D, Sliwkowski MX. Ligand-independent HER2/HER3/PI3K complex is disrupted by trastuzumab and is effectively inhibited by the PI3K inhibitor GDC-0941. Cancer Cell 2009;15:429-440. This paper demonstrated that the mechanism of action for trastuzumab is through disruption of the HER2/ HER3 complex, and that resistance could be overcome by inhibiting the PI3K pathway. [PubMed: 19411071]

23. Yuan TL, Cantley LC. PI3K pathway alterations in cancer: variations on a theme. Oncogene 2008;27:5497-5510. [PubMed: 18794884]

24. Faber AC, Li D, Song Y, Liang MC, Yeap BY, Bronson RT, Lifshits E, Chen Z, Maira SMCGE, et al. Differential induction of apoptosis in HER2 and EGFR addicted cancers following PI3K inhibition. Proc Natl Acad Sci U S A. 2009 Oct 22; [Epub ahead of print].

25. Costa DB, Halmos B, Kumar A, Schumer ST, Huberman MS, Boggon TJ, Tenen DG, Kobayashi S. BIM mediates EGFR tyrosine kinase inhibitor-induced apoptosis in lung cancers with oncogenic EGFR mutations. PLoS Med 2007;4:1669-1679. discussion 1680. [PubMed: 17973572]

26. Cragg MS, Kuroda J, Puthalakath H, Huang DC, Strasser A. Gefitinib-induced killing of NSCLC cell lines expressing mutant EGFR requires BIM and can be enhanced by BH3 mimetics. PLoS Med 2007;4:1681-1689. discussion 1690. [PubMed: 17973573]

27. Deng J, Shimamura T, Perera S, Carlson NE, Cai D, Shapiro GI, Wong KK, Letai A. Proapoptotic BH3-only BCL-2 family protein BIM connects death signaling from epidermal growth factor receptor inhibition to the mitochondrion. Cancer Res 2007;67:11867-11875. [PubMed: 18089817]

28. Gong Y, Somwar R, Politi K, Balak M, Chmielecki J, Jiang X, Pao W. Induction of BIM is essential for apoptosis triggered by EGFR kinase inhibitors in mutant EGFR-dependent lung adenocarcinomas. PLoS Med 2007;4:e294. [PubMed: 17927446] 
29. Vasudevan KM, Barbie DA, Davies MA, Rabinovsky R, McNear CJ, Kim JJ, Hennessy BT, Tseng $\mathrm{H}$, Pochanard P, Kim SY, et al. AKT-independent signaling downstream of oncogenic PIK3CA mutations in human cancer. Cancer Cell 2009;16:21-32. [PubMed: 19573809]

30. Sos ML, Fischer S, Ullrich R, Peifer M, Heuckmann JM, Koker M, Heynck S, Stuckrath I, Weiss J, Fischer F, et al. Identifying genotype-dependent efficacy of single and combined PI3K- and MAPKpathway inhibition in cancer. Proc Natl Acad Sci U S A 2009;106:18351-18356. [PubMed: 19805051]

31. Hoeflich KP, O’Brien C, Boyd Z, Cavet G, Guerrero S, Jung K, Januario T, Savage H, Punnoose E, Truong $\mathrm{T}$, et al. In vivo antitumor activity of MEK and phosphatidylinositol 3-kinase inhibitors in basal-like breast cancer models. Clin Cancer Res 2009;15:4649-4664. [PubMed: 19567590]

32. Mirzoeva OK, Das D, Heiser LM, Bhattacharya S, Siwak D, Gendelman R, Bayani N, Wang NJ, Neve RM, Guan Y, et al. Basal subtype and MAPK/ERK kinase (MEK)-phosphoinositide 3-kinase feedback signaling determine susceptibility of breast cancer cells to MEK inhibition. Cancer Res 2009;69:565-572. [PubMed: 19147570] 


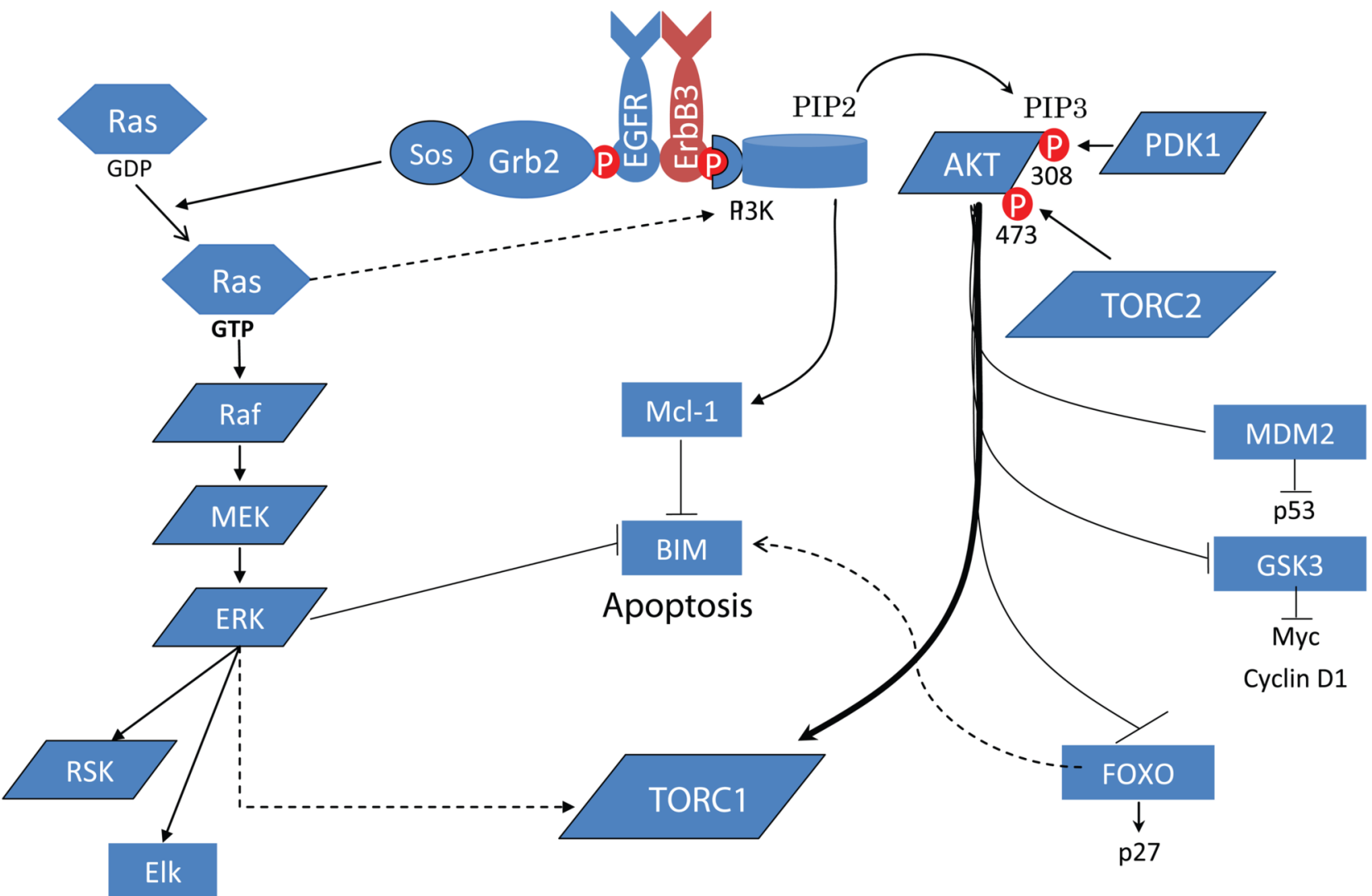

Figure 1.

Schematic of how the PI3K-AKT and MEK-ERK pathways regulate apoptosis in EGFR driven cancers. 